\title{
RANCANG BANGUN ADMIISTRASI STOK COUPLER PT KOMPACINDO AREA UTAMA
}

\author{
Khaasanah $^{1 *}$, Mas Arif Syaeffudin Habsi ${ }^{1}$, Imam Maliki ${ }^{1}$, Yefri MC Liu ${ }^{1}$, Ismail ${ }^{1}$ \\ ${ }^{1}$ Prodi Sistem Informasi, STMIK Indonesia Jakarta \\ Email :*khasanah.pase@gmail.com
}

\begin{abstract}
PT. Kompacindo Area Utama is one of the companies located in Sunter, North Jakarta engaged in the sale of heavy equipment parts in the form of coupler. The company initially used stock sheets in stock management, documentation for incoming goods and also out still using manual sheets that are vulnerable to lost, damaged and non-backed up, and mail and invoice creation still using Microsoft Excel. For that made a program that can improve the management of stock of goods and documentation of letters and invoices. The resulting system can manage the stock of goods including the documentation of incoming goods, goods out, and then can help the administration of printing letters and invoices. The Stock Coupler Administration System In PT.Kompacindo Area Utama is created using a website-based application using PHP as a programming language and MySQL is used to handle and manage databases.
\end{abstract}

Keywords : System Administration, Stock Goods, PHP \& MySQL

Abstrak : PT. Kompacindo Area Utama merupakan salah satu perusahaan yang berlokasi di Sunter, Jakarta Utara bergerak dibidang penjualan suku cadang alat berat berupa coupler. Perusahaan ini awalnya menggunakan lembaran stok dalam pengelolaan stok barang, dokumentasi untuk barang masuk dan juga keluar masih menggunakan lembaran manual sehingga rentan hilang, rusak dan tidak dapat dicadangkan, serta pembuatan surat jalan dan invoice masih menggunakan Microsoft Excel. Untuk itu dibuat suatu program yang dapat memperbaiki pengelolaan stok barang dan dokumentasi surat jalan dan invoice. Sistem yang dihasilkan dapat melakukan pengelolaan stok barang meliputi dokumentasi barang masuk, barang keluar, kemudian dapat membantu administrasi mencetak surat jalan dan invoice. Sistem Administrasi Stok Coupler Pada PT.Kompacindo Area Utama dibuat menggunakan aplikasi berbasis website menggunakan PHP sebagai bahasa pemrograman dan MySQL digunakan untuk menangani dan mengelola database.

Kata kunci : Sistem Administrasi, Stok Barang, PHP \& MySQL

\section{PENDAHULUAN}

Perkembangan teknologi yang
semakin canggih menyebabkan
kebutuhan akan informasi yang tepat,
cepat dan akurat menjadi sangat penting.

Aplikasi berbasis website telah banyak mem-berikan sumbangan positif diberbagai bidang, salah satunya pada bidang UMKM (Usaha Mikro Kecil dan Menengah).[1][2][3][4]

PT. Kompacindo Area Utama 
DOI: https://doi.org/10.33330/jurteksi.v6i1.367

Available online at http://jurnal.stmikroyal.ac.id/index.php/jurteksi

merupakan sebuah perusahaan yang bergerak dibidang penjualan suku cadang berupa coupler. Sebagai perusahaan yang sedang berkembang PT. Kompacindo Area Utama merupakan salah satu penyuplai coupler terpercaya sehingga penting untuk dilakukan pengembangan sistem stok coupler. Dalam penyediaan stok coupler untuk pelanggan, perusahaan tersebut memiliki coupler dengan berbagai ukuran mulai dari $1 / 4$ inch hingga 2 inch yang diperuntukan berbagai tipe mesin hidrolik.

Dalam pengelolan stok dan pembuatan invoice masih menggunakan lembaran kartu stok dan Microsoft Excel, sehingga hal ini menjadi suatu kendala yang membuat proses pencarian barang menjadi lama dan informasi persediaan stok kurang akurat. Hal ini menjadi masalah terpenting pada PT. Kompacindo Area dalam pengelolaan stok barang yang harus dilakukan secara baik dan tepat agar tidak terjadi kerugian, sehingga menjadikan PT. Kompacindo Area membutuhkan sebuah sistem yang dapat mendukung aktifitas dalam proses dokumentasi barang masuk dan barang keluar, pencarian data barang, pembuatan kwitansi pembayaran (invoice) dan memberikan kemudahan dalam pembuatan surat jalan.

Untuk memudahkan rancangan sistem yang akan dibangun maka data stok coupler diambil dari data-data yang telah ada sehingga sistem ini lebih membangun dan memberikan kemudahan untuk pengguna pada PT. Kompacindo Area Utama.

\section{METODE}

Diagram aliran data merupakan model dari sistem untuk menggambarkan pembagian sistem ke modul yang lebih kecil sehingga memberikan keuntungan menggunakan diagram aliran data adalah memudahkan pengguna (user) yang kurang menguasai bidang komputer untuk mengerti sistem yang akan dikerjakan. [5][6][7][8]

Untuk pengembangan sistem pada penelitian ini digunakanlah metode Waterfall sebagaimana di gambarkan pada gambar 1, bahwasannya metoda Waterfall merupakan suatu metodologi pengembangan perangkat lunak yang mengusulkan pendekatan kepada perangkat lunak sistematik dan sekuensial yang mulai pada tingkat kemajuan sistem pada seluruh analisis, design, kode, pengujian dan pemeliharaan.[9]

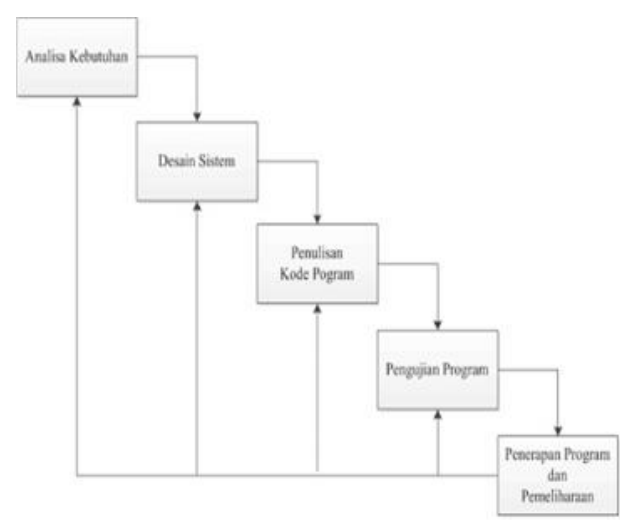

Gambar 1. Metode Waterfall

Langkah-langkah yang harus dilakukan pada metodologi Waterfall adalah sebagai berikut:

a. Analisa Kebutuhan, dimana seluruh kebutuhan software harus bisa didapatkan dalam fase ini, termasuk didalamnya kegunaan software yang diharapkan pengguna dan batasan software. Informasi ini biasanya dapat diperoleh melalui wawancara, survey atau diskusi. Informasi tersebut dianalisis untuk mendapatkan dokumentasi kebutuhan pengguna 
DOI: https://doi.org/10.33330/jurteksi.v6i1.367

Available online at http://jurnal.stmikroyal.ac.id/index.php/jurteksi

untuk digunakan pada tahap selanjutnya.

b. Desain Sistem, dimana pada tahap ini dilakukan sebelum melakukan coding. Tahap ini bertujuan untuk memberikan gambaran apa yang seharusnya dikerjakan dan bagaimana tampilannya. Tahap ini membantu dalam menspesifikasikan kebutuhan hardware dan sistem serta mendefinisikan arsitektur sistem secara keseluruhan.

c. Penulisan Kode Program, dimana dalam tahap ini dilakukan pemrograman. Pembuatan software dipecah menjadi modul-modul kecil yang nantinya akan digabungkan dalam tahap berikutnya. Selain itu dalam tahap ini juga dilakukan pemeriksaaan terhadap modul yang dibuat, apakah sudah memenuhi fungsi yang diinginkan atau belum.

d. Pengujian Program, dimana di tahap ini dilakukan penggabungan modulmodul yang sudah dibuat dan dilakukan pengujian ini dilakukan untuk mengetahui apakah software yang dibuat telah sesuai dengan desainnya dan masih terdapat kesalahan atau tidak.

e. Penerapan Program dan Pemeliharaan, dimana pada tahap ini merupakan tahap terakhir dalam model waterfall. Software yang sudah jadi dijalankan serta dilakukan pemeliharaan. Pemeliharaan termasuk dalam memperbaiki kesalahan yang tidak ditemukan pada langkah sebelumnya. Perbaikan implementasi unit sistem dan peningkatan jasa sistem sebagai kebutuhan baru.

Metode Pengumpulan data yang digunakan dalam penelitian ini adalah :

a. Wawancara, pada metode ini peneliti berhadapan langsung dengan pihak
PT. Kompacindo Area Utama untuk mendapatkan informasi permasalahan secara lisan.

b. Observasi, pada metode pengumpulan data dilakukan pengamatan secara langsung terhadap suatu kegiatan yang sedang berjalan pada PT. Kompacindo Area Utama.

c. Studi Pustaka, pada tahap ini dilakukan pencarian bahan dari berbagai literatur dengan maksud agar mendapatan informasi tanpa batas yang sangat dibutuhkan.

\section{HASIL DAN PEMBAHASAN}

\section{Analisis Sistem Berjalan}

Analisis sistem berjalan berisi rangkaian analisa prosedur sistem yang berjalan pada PT. Kompacindo Area Utama, dimana terdiri dari mendefinisikan masalah, mengidentifikasi penyebabnya, menentukan solusi, dan mengidentifikasi kebutuhan informasi yang harus memenuhi dengan solusi sistem sehingga setiap sistem yang akan dibangun dapat dievaluasi dan dapat dibuat satu usulan untuk pemgembangan sistem atau pembangunan sistem yang baru.

Analisis dokumen sebagaimana pada tabel 1 merupakan kegiatan menganalisis dan mempelajari dokumendokumen yang digunakan dan mengalir pada sistem informasi yang sedang berjalan di PT. Kompacindo Area Utama dengan tujuan menganalisa dokumen yang digunakan sebagai acuan pada tahap pengembangan. 
Tabel 1. Analisa Dokumen

\begin{tabular}{|c|c|}
\hline kn & Lemb \\
\hline Fungsi & $\begin{array}{l}\text { Menginformasikan } \\
\text { barangmasuk dan keluar }\end{array}$ \\
\hline Sumber & : Kepala Gudang \\
\hline Rangkap & : 1 (Satu) \\
\hline Distribusi & Administrasi \\
\hline Frekuensi & $\begin{array}{l}\text { Setiap adanya barang } \\
\text { masuk dari pemasok. }\end{array}$ \\
\hline Form & $\begin{array}{l}\text { Format dokumen } \\
\text { menggunakan lembaran } \\
\text { kartu stok. }\end{array}$ \\
\hline $\begin{array}{l}\text { Hasil } \\
\text { Analisa }\end{array}$ & $\begin{array}{l}\text { Setiap barang masuk } \\
\text { dari pemasok dan } \\
\text { barang keluar untuk } \\
\text { pelanggan harus dicatat } \\
\text { dalam lembaran kartu } \\
\text { stok. }\end{array}$ \\
\hline
\end{tabular}

\begin{tabular}{|c|c|}
\hline & \\
\hline Fungsi & $\begin{array}{l}\text { Menginformasikan data } \\
\text { barang masuk dan } \\
\text { keluar per bulan. }\end{array}$ \\
\hline Sumber & : Kepala Gudang \\
\hline angkap & $: 1$ (Satu) \\
\hline istribusi & $\therefore \mathrm{Ad}$ \\
\hline Frekuensi & $:$ Set \\
\hline Format & : Mic \\
\hline $\begin{array}{l}\text { Iasil } \\
\text { nalisa }\end{array}$ & $\begin{array}{l}\text { Laporan dibuat oleh } \\
\text { kepala gudang dan } \\
\text { dikirim ke administrasi } \\
\text { setiap bulan. }\end{array}$ \\
\hline & Tahunan \\
\hline Fun & $\begin{array}{l}\text { Menginformasikan data } \\
\text { barang masuk dan } \\
\text { keluar per tahun. }\end{array}$ \\
\hline Sumber & $:$ Admi \\
\hline angkap & $: 1(s$ \\
\hline & Dir \\
\hline Frekuensi & $\mathrm{Sc}$ \\
\hline Format & : Microsoft Office Excel \\
\hline & dibuat \\
\hline & \begin{tabular}{lrr}
\multicolumn{2}{l}{ Administrasi } & dan \\
dikirim ke & direktur \\
setiap tahun. & \\
\end{tabular} \\
\hline
\end{tabular}

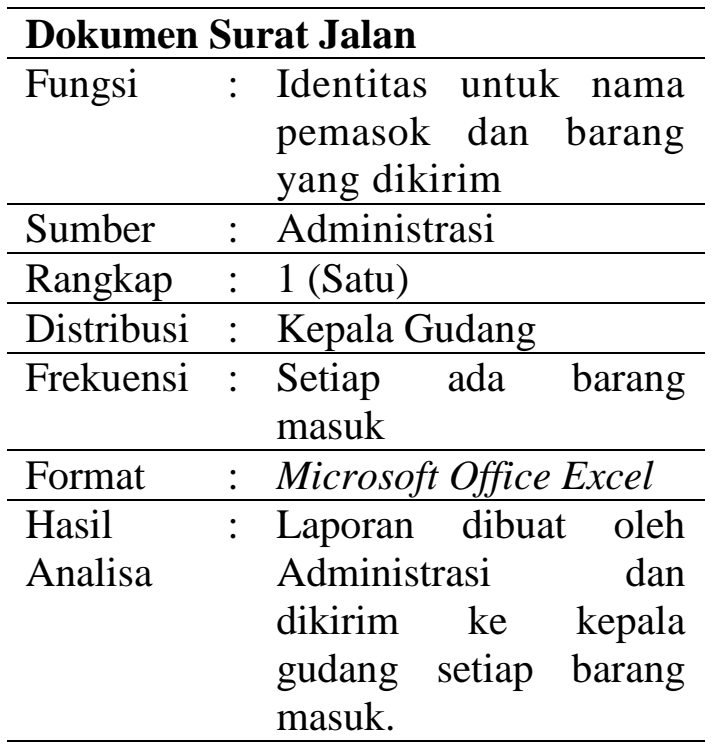

\begin{tabular}{lll}
\hline $\begin{array}{l}\text { Dokumen } \\
\text { (Invoice) }\end{array}$ & Kwitansi Pembayaran \\
\hline Fungsi & $:$ Bukti Pembayaran \\
\hline Sumber & $:$ Administrasi \\
\hline Rangkap & $:$ 1 (Satu) \\
\hline Distribusi & $:$ Direktur \\
\hline Frekuensi & $:$ Setiap ada pembelian \\
\hline Format & $:$ Microsoft Office Excel \\
\hline Hasil & $:$ Laporan dibuat oleh \\
Analisa & $\begin{array}{l}\text { Administrasi dan } \\
\text { dikirim ke direktur } \\
\end{array}$ \\
& setiap ada pembelian. \\
\hline
\end{tabular}

Analisis proses bisnis yang
berjalan merupakan kegiatan
menganalisa atau memahami proses-
proses bisnis yang sedang berjalan saat
ini di perusahaan yang diteliti. Selain
memahami proses yang berjalan dengan
gambar 2 digunakan flowmap diagram
dalam menjabarkan proses bisnis yang
berjalan.
berjalan merupakan kegiatan menganalisa atau memahami prosesproses bisnis yang sedang berjalan saat ini di perusahaan yang diteliti. Selain memahami proses yang berjalan dengan gambar 2 digunakan flowmap diagram dalam menjabarkan proses bisnis yang berjalan. 


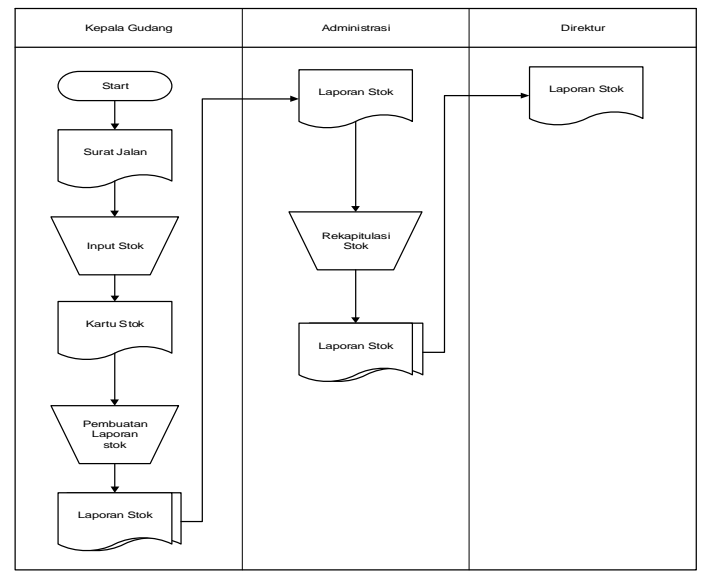

Gambar 2. Flowmap sistem berjalan pada PT. Kompacindo Area Utama

Penjelasan dari tinjauan sistem berjalan adalah sebagai berikut :

1. Kepala gudang menerima surat jalan.

2. Surat jalan dijadikan sebagai dokumen acuan untuk mencatat stok barang kedalam kartu stok.
3. Salinan kartu stok diberikan kepada bagian administrasi.

4. Pembuatan laporan stok bulanan dibuat oleh kepala gudang 2 rangkap, 1 lembar untuk kepala gudang dan 1 lembar dilaporkan kepada bagian administrasi.

5. Administrasi melakukan rekapitulasi stok kemudian dibuat laporan stok tahunan 2 rangkap, 1 lembar untuk administrasi dan 1 lembar untuk direktur.

Analisis kebutuhan sistem yang dijabarkan pada tabel 2 sangat dibutuhkan guna menunjang penerapan sistem baru, apakah sudah sesuai dengan kebutuhan user, apakah sudah sesuai dengan tujuan yang ingin dicapai melalui perancangan sistem yang dirancang.

Tabel 2. Analisa Kebutuhan

\section{Kebutuhan Non Fungsional}

a. Sistem ini harus bisa dapat melakukan pengelolaan data seperti input, update, delete datastok serta mencetak kwitansi pembayaran (invoice).

b. Sistem ini dapat menginformasikan kepada kepala gudang bahwa jumlah coupler mencapai stok minimum.

c. Output yang dihasilkan berupa laporan bulanan dan tahunan untuk barang masuk dan keluar.

\section{Kebutuhan Non Fungsional}

a. Kebutuhan perangkat keras (hardware) untuk sistem ini adalah komputer (CPU, Keyboard, Mouse, Monitor) dengan spesifikasi minimum Processor Core i3 dengan RAM 2GB, VGA onboard, Harddisk 500 GB.

b. Kebutuhan perangkat lunak (software) yang diperlukan untuk membuat sistem ini adalah Dreamweaver, Xampp, Windows 7 Ultimate.

\section{Kebutuhan Sumber Daya Manusia (Brainware)}

Kebutuhan sumber daya manusia dibutuhkan untuk dapat menjalankan sistem ini yaitu admin dan penanggung jawab perusahaan yang mampu dan terbiasa mengoprasikan komputer.

\begin{aligned} \hline Berdasarkan uraian prosedur & Area Utama, maka pada tabel 3 \\ sistem untuk mendapatkan informasi & diterapkan kerangka kerja pemecahan \\ yang sedang berjalan di PT. Kompacindo & masalah dengan menggunakan PIECES \end{aligned}


dan pada tabel 4 diterapkan analisis

Cause and Effect.

Tabel.3 Analisa Pieces Sistem pada PT. Kompacindo Area Utama

\begin{tabular}{llll}
\hline NO & \multicolumn{2}{c}{ Kerangka PIECES } & \multicolumn{2}{c}{ Keterangan } \\
\hline 1. & $\begin{array}{l}\text { Kinerja } \\
(\text { Performace })\end{array}$ & Sistem & $\begin{array}{l}\text { Barang yang masuk harus dicatat secara manual ke } \\
\text { dalam buku stok sehingga mudah rusak dan rentan } \\
\text { hilang. }\end{array}$ \\
\hline 2. & $\begin{array}{l}\text { Informasi yang di } \\
\text { Hasilkan(Information) }\end{array}$ & $\begin{array}{l}\text { Informasi stok barang masih berupa lembaran stok } \\
\text { dan kurang terstruktur. }\end{array}$ \\
\hline 3. & $\begin{array}{l}\text { Nilai } \\
\text { Sistem (Economic) }\end{array}$ & Ekonomis & Memerlukan anggaran pembelian kartu stok. \\
\hline 4. & $\begin{array}{l}\text { Kontrol } \\
\text { (Control) }\end{array}$ & Sistem & $\begin{array}{l}\text { Informasi stok yang dibawah minimum masih kurang } \\
\text { diawasi sehinga beberapa permintaan dari } \\
\text { pelanggan tidak terpenuhi }\end{array}$ \\
\hline 5. & $\begin{array}{l}\text { Efisiensi } \\
\text { (Effisiency) }\end{array}$ & Sistem & $\begin{array}{l}\text { Penggunaan kartu stok kurang efisien karena mudah } \\
\text { rusak dan rentan hilang }\end{array}$ \\
\hline 6. & $\begin{array}{l}\text { Pelayanan } \\
\text { (Service) }\end{array}$ & Sistem & $\begin{array}{l}\text { Keterbatasan informasi stok minimum coupler yang } \\
\text { berdampak pada tidak terpenuhinya beberapa } \\
\text { permintaan pelanggan sehingga banyak pelanggan } \\
\text { yang pindah ke suplier lainnya }\end{array}$ \\
\hline
\end{tabular}

Tabel 4. Cause and Effect Sistem Informasi PT. Kompacindo Area Utama

\section{Problem Cause-Effect Analysis}

Proses dokumentasi Cause : Kepala Gudang melakukan pengelolaan stok barang stok barang masih menggunakan lembaran kartu stok

manual

Effect : Kartu stok sangat rentan hilang, rusak da1n tidak dapat dicadangkan

Tujuan Sistem : Membuat sistem informasi yang dapat membantu proses pengelolaan stok barang

Batasan Sistem : Sistem Informasi Administrasi stok coupler ini membahas mengenai perubahan sistem dari manual menjadi terkomputerisasi.

Belum adanya Cause : Pada proses sebelumnya tidak ada pemberitahuan pemberitahuan mengenai jumlah stok minimum

mengenai jumlah Effect : Persediaan untuk pelanggan tidak optimal

stok minimum Tujuan Sistem : Membuat sistem informasi untuk menginformasikan kepala gudang bahwa stok telah mencapai batas minimum

Batasan Sistem : Data stok coupler diambil dari data-data yang telah ada dan Sistem Informasi Administrasi ini hanya dipergunakan di PT. Kompacindo Area Utama

Pembuatan kwitansi Cause : Admin masih menggunakan microsoftexceldalam pembayaran pembuatan invoice

(invoice)

Effect : Tidak terintegrasi dengan stok digudang

menggunakan

Tujuan Sistem : Membuat sebuah sistem yang dapat mencetak microsoftexcel invoice (kwitansi pembayaran) agar memberikan kemudahan dalam pembuatan invoice 
DOI: https://doi.org/10.33330/jurteksi.v6i1.367

Available online at http://jurnal.stmikroyal.ac.id/index.php/jurteksi

\section{Perancangan Sistem}

Kegiatan yang dilakukan pada tahap ini yaitu merancang diagram konteks pada gambar 4, Use Case Diagram Usulan pada gambar 5, Class Diagram Usulan pada gambar 6, Pemodelan Data Sistem Yang Diusulkan pada gambar 7 .

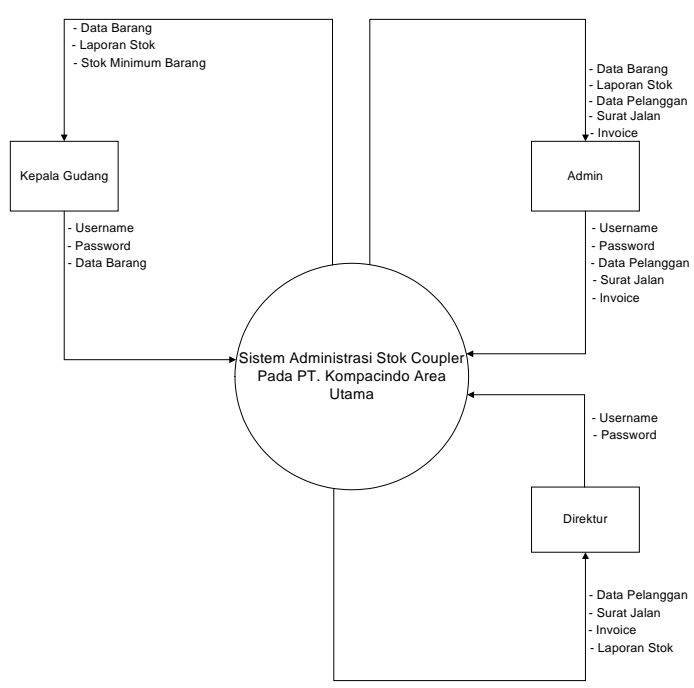

Gambar 4. Diagram Konteks Sistem Yang Diusulkan

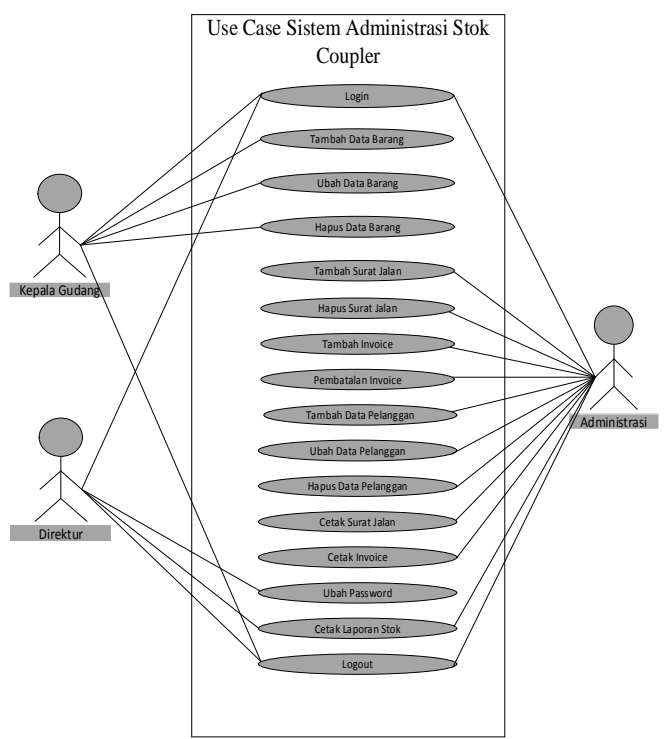

Gambar 5. Use Case Diagram Sistem Yang Diusulkan

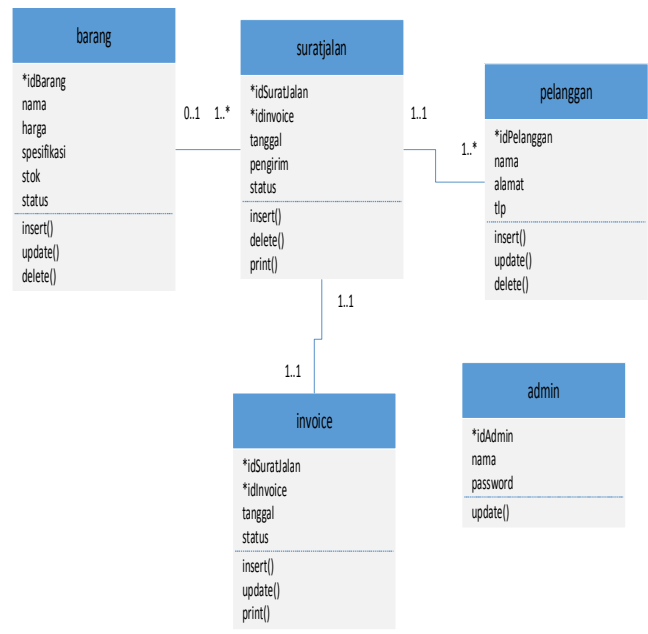

Gambar 6. Class Diagram Sistem yang Diusulkan

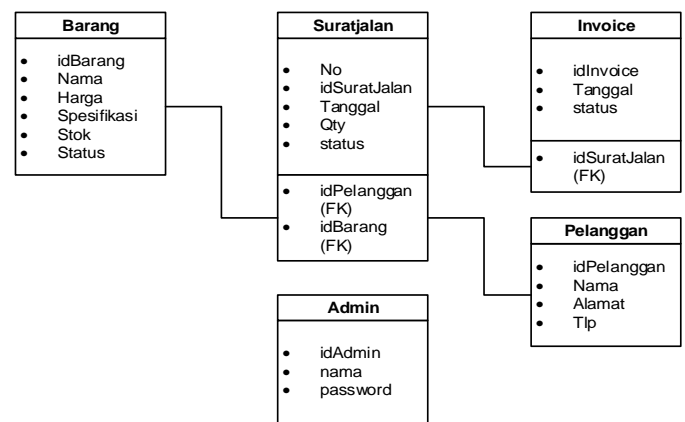

Gambar 7. LRS (Logical Relational Structure)

\section{Perancangan Antar Muka}

Pada bagian perancangan struktur menu inilah tahapan proses peran pengguna, pada gambar 8 menunjukkan Struktur Tampilan Halaman yang di usulkan di bangun pada PT.Kompacindo Area Utama.

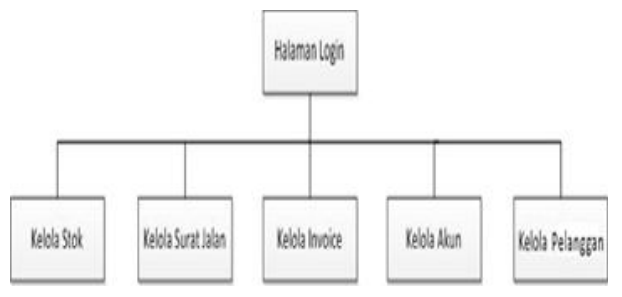

Gambar 8. Struktur Tampilan Halaman yang di usulkan di bangun pada PT.Kompacindo Area Utama 
DOI: https://doi.org/10.33330/jurteksi.v6i1.367

Available online at http://jurnal.stmikroyal.ac.id/index.php/jurteksi

Pada bagian perancangan antar muka inilah tahapan proses peran pengguna, merancang struktur database, struktur menu, dan pada gambar 9 merupakan tampilan halaman layar form login, pada gambar 10 merupakan tampilan halaman layar tambah data barang, pada gambar 11 merupakan tampilan halaman layar tambah data pelanggan, pada gambar 12 merupakan tampilan halaman layar hapus surat jalan, pada gambar 13 merupakan tampilan halaman layar cetak surat jalan, pada gambar 14 merupakan tampilan layar list invoice, pada gambar 15 merupakan tampilan layar cetak invoice, pada gambar 16 merupakan halaman layar pembayatalan invoice, pada gambar 17 merupakan rancangan halaman layar ubah password.

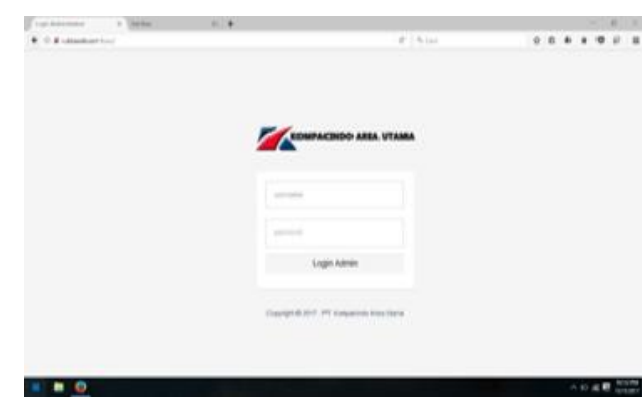

Gambar 9. Halaman Layar Form Login

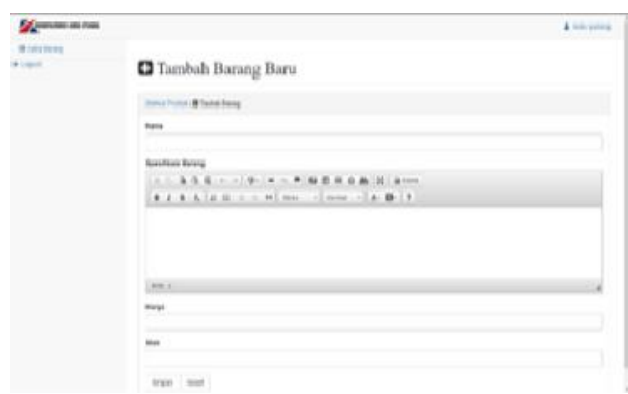

Gambar 10. Halaman Layar Tambah Data Barang

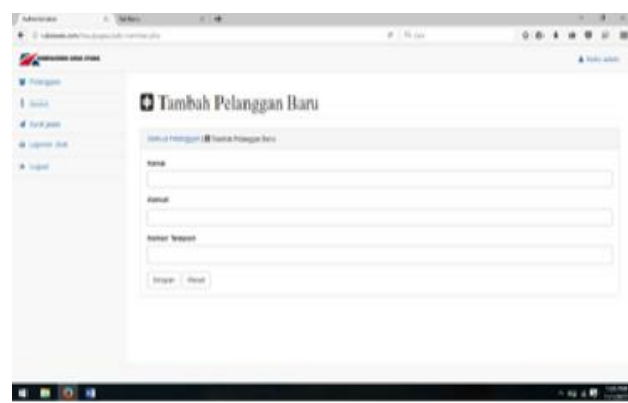

Gambar 11. Halaman Layar Tambah Data Pelanggan

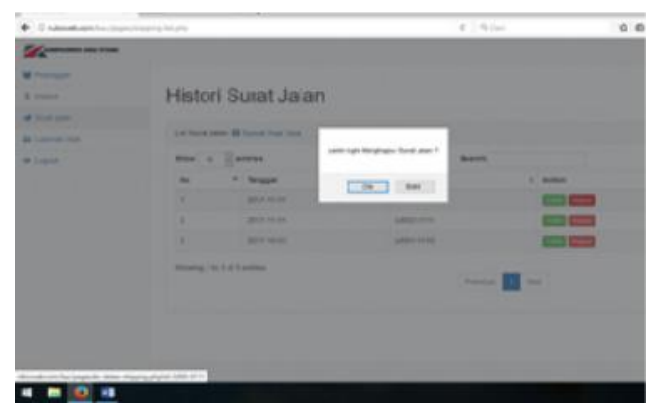

Gambar 12. Halaman Layar Hapus Surat Jalan

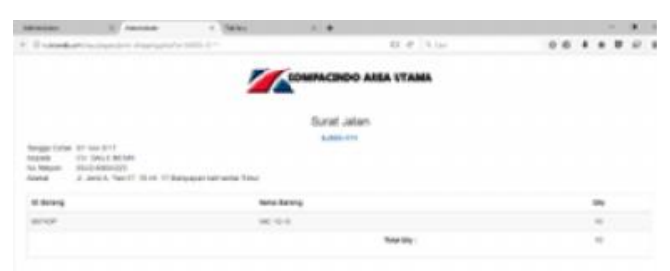

Gambar 13. Halaman Layar Cetak Surat Jalan

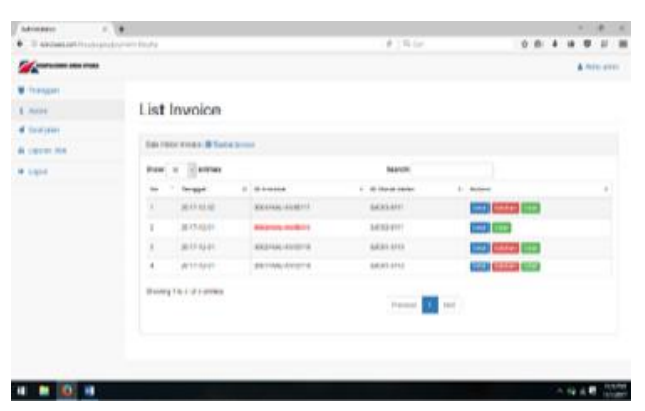

Gambar 14. Halaman Layar List Invoice 
DOI: https://doi.org/10.33330/jurteksi.v6i1.367

Available online at http://jurnal.stmikroyal.ac.id/index.php/jurteksi

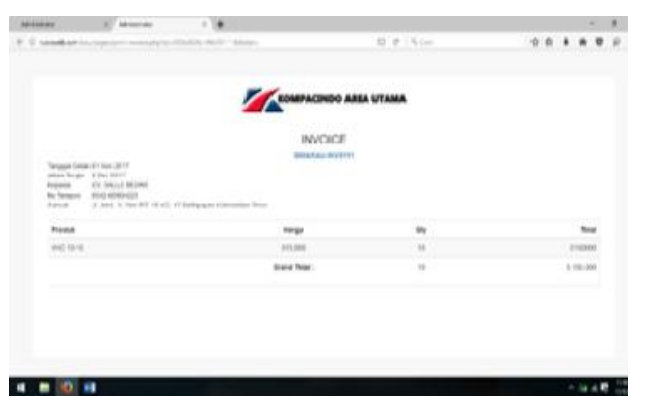

Gambar 15. Halaman Layar Cetak Invoice

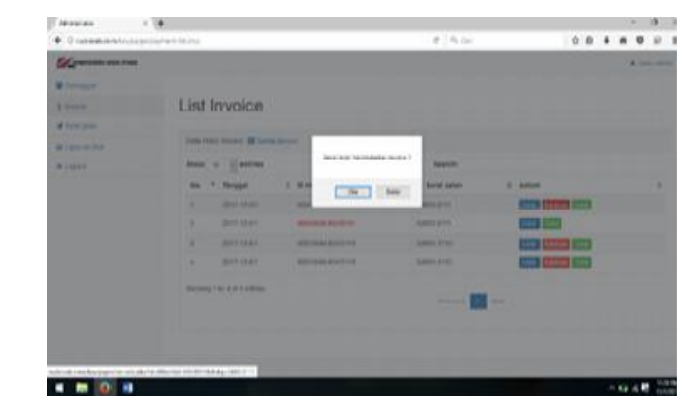

Gambar 16. Halaman Layar Pembatalan Invoice

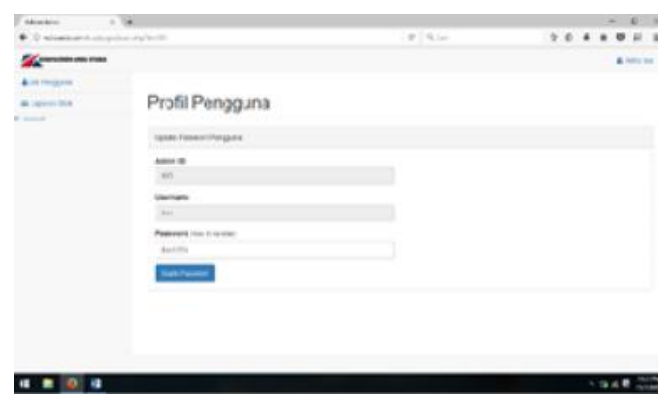

Gambar 17. Halaman Layar Ubah Password

\section{SIMPULAN}

Dengan adanya sistem yang dihasilkan dapat melakukan pengelolaan stok barang meliputi dokumentasi barang masuk dan barang keluar pada PT. Kompacindo Area Utama sehingga dapat membantu administrasi mencetak surat jalan dan invoice. Namun diperlukan adanya pelatihan dan pengawasan bagi pengguna yang akan mengoperasikan program ini, sehingga dapat memiliki kesiapan dan pemahaman dalam mengoperasikan sistem tersebut dengan baik dan dapat memperbaiki apabila ada masalah yang terjadi dengan sistem. Diharapkan dilakukan pencadangan terhadap data yang ada secara berkala untuk mencegah terjadinya hal-hal yang tidak diinginkan seperti kerusakan ataupun kehilangan data.

\section{UCAPAN TERIMA KASIH}

Ucapan terima kasih kami ucapkan kepada :

a. Kepada Chief Editor JURTEKSI (Jurnal Teknologi dan Sistem Informasi), yang merupakan Jurnal Penelitian dan Kajian Ilmiah yang diterbitkan oleh STMIK Royal Kisaran yang telah memberikan kesempatannya kepada kami untuk dapat berpartisipasi dalam jurnal yang Bapak/Ibu kelola.

b. Kepada Bapak/Ibu Editor dan Bapak/Ibu Reviewer JURTEKSI (Jurnal Teknologi dan Sistem Informasi), yang telah memberikan kesempatannya kepada kami untuk dapat berpartisipasi dalam jurnal yang Bapak/Ibu kelola.

c. Bapak Prof. Dr . H. Faisal Santiago, S.H., M.M., selaku Ketua Yayasan YAPMI dan Bapak Djoko Harsono,S.Kom., MM., M.Kom, selaku Ketua STMIK Indonesia Jakarta yang telah membantu baik dana, peralatan maupun tempat penelitian dan laboratorium.

d. Rekan-rekan satu team dan rekanrekan sejawat yang tidak bisa diebutkan satu per satu yang telah mensupport dan bekerjasama sampai penelitian ini selesai 


\section{DAFTAR PUSTAKA}

[1] S. Komputer, N. Putu, H. Valentina, E. M. Dharma, and N. M. Estiyanti, "Rancang Bangun Sistem Informasi Penjualan dan Penerimaan Kas Berbasis Web Pada CV Bali Shanti," vol. 14, no. 1, pp. 43-64, 2019.

[2] A. Suryadi and S. I. Nurmawati, "Sistem Informasi Penjualan Kerajinan Berbasis Web Menggunakan Model V-Model ( Studi Kasus Karang Taruna Pelitamas Banjarnegara )," vol. 3, no. 2, pp. 268-276, 2018.

[3] S. F. Junanda and D. Safitri, "Sistem Informasi Penjadwalan Laboratorium Berbasis Web ( Studi Kasus : Laboratorium Multimedia Politeknik Aceh Selatan )," Vol. 2, no. 2, pp. 132139, 2018.

[4] D. B. Napitupulu, "Perancangan Sistem Informasi Pelatihan Koperasi Uji Mutu Berbasis Web," J. Sist. Inf., vol. 4, no. 1, p. 67, 2012.

[5] R. Afyenni, D. Jurusan, T. Informasi, and P. Negeri,
"Perancangan Data Flow Diagram Untuk Sistem Informasi Sekolah ( Studi Kasus Pada Sma Pembangunan Laboratorium Unp )," vol. 2, no. 1, 2014.

[6] P. Toko, S. Jaya, E. Pacitan, I. N. Indah, and K. Kunci, "Pembuatan sistem informasi penjualan pada toko sehat jaya elektronik pacitan," vol. 10, no. 2, 2013.

[7] B. Nugraha et al., "Perancangan Dan Pengujian Miniatur Lift Berbasis Identifikasi Lantai," pp. 211-216.

[8] P. D. Astuti, "Sistem Informasi Penjualan Obat Pada Apotek Jati Farma Arjosari," Indones. J. Comput. Sci. - Speed 16 FTI UNSA Vol 10 No 1 - Mei 2013 ijcss.unsa.ac.id, vol. 10, no. 1, pp. 142-147, 2013.

[9] R. R. Rerung and Y. R. Ramadhan, "Rancang Bangun Sistem Informasi Akademik dalam Penerapan Smart Campus untuk Meningkatkan Pelayanan Akademik," vol. 3, no. 2, pp. 191210, 2018. 